\title{
Relationship between Specific Surface Parameters and Brightness Temperature in Metropolitan Area
}

\author{
CHEN Fu, ZENG Yuanwen, LIANG Shuang \\ China University of Mining and Technology, Jiangsu Key Laboratory of Resources and Environmental Information Engineering, \\ Low Carbon Energy Institute of CUMT \\ Xuzhou, China \\ chenfu@cumt.edu.cn
}

\begin{abstract}
Based on Landsat TM images the brightness temperature (Tb), and urban land use information, and normalized difference vegetation index (NDVI) on vegetation cover surface, and normalized difference built-up index (NDBI) on construction were obtained, the relationships between NDVI and Tb, NDBI and Tb were discussed by constructing circular feature profiles. The results show that: (1) there is a significantly negative correlation between NDVI and $\mathrm{Tb}$, and a significantly positive correlation between NDBI and $T b$, the correlation increase with the increasing of profile radius; (2) the correlation between NDVI and Tb is greater than that between NDBI and Tb, but the contribution of Tb NDVI is less than NDBI. This study can provide a reference for Xuzhou's urban planning and green space planning in the future.
\end{abstract}

Keywords-normalized difference vegetation index, normalized difference built-up index, brightness temperature, feature profile.

\section{INTRODUCTION}

With the increasing urbanization, urban heat island effect arising from it has been widely concerned[1]. The urbanization process is substantially the process of land use type transformation[2]. Along with the continuous development of city, urban heat island effect is more and more intense and generates deeper and deeper influence on People's daily lives [3]. The development of remote sensing technology provides a new means for the study of urban heat island effect; remote sensing image is utilized to inverse land surface temperature for exploring the space distribution rule of urban heat island [4]; and NDVI (Normalized Difference Vegetation Index) is introduced to characterize the coverage degree of vegetation in order to explore the relation between the coverage degree of vegetation and land surface temperature[5]. NDBI (Normalized Difference Building. Index) proposed by Zhayong[6] provides new means for the study of urban heat island effect, and later the study of relation of NDBI and other character parameters and land surface temperature appear in succession[7]. On the basis of predecessors' studies, the relation between land surface character parameters and land surface temperature is explored in the paper. It is considered in the paper that NDVI can reflect vegetation coverage rather precisely, but the precision is not high to characterize other land use type with NDVI; for the same reason, NDBI is the parameter to characterize building land and causes errors in charactering other land use types; at the same time land surface temperatures vary from different land use types; so that the precision of study result will be reduced if the whole study region is considered generally together. Owing to this, the land use types in the study region are considered separately, land surface parameter with optimal correlation with the land use type is extracted according to the specific land use type, NDVI is extracted in vegetation coverage land, NDBI is extracted in building land, and the space distribution relation of NDVI, NDBI and land surface temperature is explored.

\section{RESEARCH METHODS}

Based on Supervised classification the land use types of study area are divided into three categories: construction land (development zone, bare ground), vegetation (forests, grasslands, crops), the water. Surface brightness temperature

$(\mathrm{Tb})$,normalized difference vegetation index (NDVI) and normalized difference building index (NDBI) were received from the remote sensing image. For the water will impact on its neighboring $\mathrm{Tb}$, take Yunlong Lake and its periphery as the study object to explore the influence radius of the water to $\mathrm{Tb}$. Considering that the NDVI is sensitive to vegetation, NDBI is sensitive to construction, so in this study exclude the influence of different land use types to NDVI、NDBI and $\mathrm{Tb}$ before discuss the relationship between $\mathrm{Tb}$ and NDVI、Tb and NDBI, that is extract NDVI on vegetation, in the same way NDBI is measured on architectural filed, then explore the relationship between these two parameters and $\mathrm{Tb}$ respectively by building feature profiles, obviating the impact of water when selected feature profiles.

\section{A. Study Area and Data Sources}

The study area in this paper is Xuzhou City, which lies between $33^{\circ} 43^{\prime} \sim 34^{\circ} 58^{\prime} \mathrm{N}$ and $116^{\circ} 22^{\prime} \sim 118^{\circ} 40^{\prime} \mathrm{E}$, covering an area of 11258 square $\mathrm{km}^{2}$.In this study, Landsat TM image of Xuzhou City was used as a data source, which was got on September 18,2010.

\section{B. Land Use/Cover Classification}

Maximum likelihood (ML) classifier was chosen to execute the land use type classification of the study area. The classification result is shown in Fig 1 


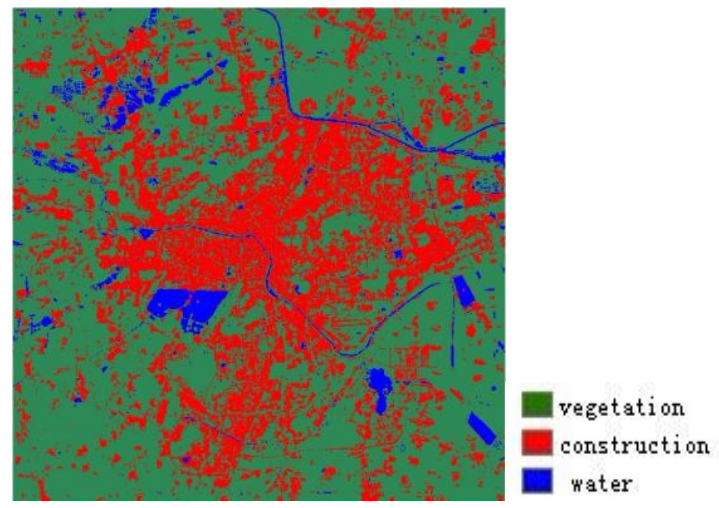

Fig 1 Land use classification map

\section{Inversion of Surface Brightness Temperature}

DN value of the sixth band of TM image was used to calculate the brightness temperature ${ }^{[8]}$, The distribution of brightness temperature in the study area is shown in Fig 2

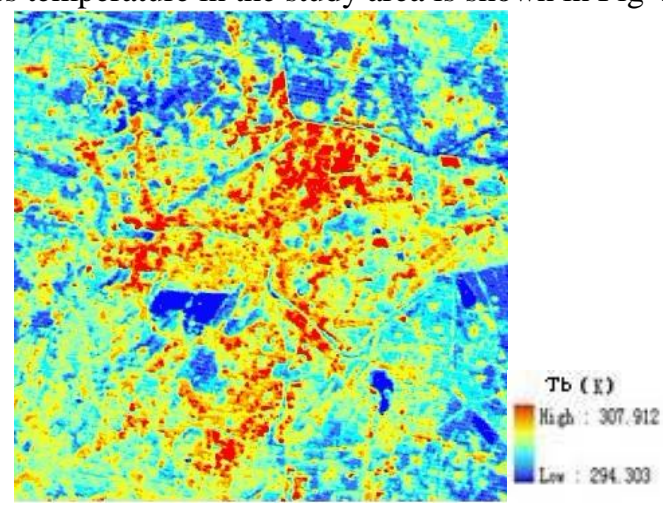

Fig 2 Distribution of brightness temperature

\section{Extract NDVI and NDBI}

NDVI is defined as follow:

$$
\text { NDVI=(TM4-TM3) / (TM4+TM3) }
$$

NDBI can be calculated from the following equation:

$$
\text { NDBI=(TM5-TM4) / (TM5+TM4) }
$$

\section{E. Structuring of Characteristic Profile}

As it is considered that the study area is located in plane region, a plurality of circular characteristic profiles are uniformly selected with the center of study area being these circles' center, and the radius difference between adjacent profiles is $0.5 \mathrm{~km}$. When structuring the characteristic profiles, first assigned a value of 1 to the part of vegetation in the land use classification figure, and other land use types are assigned a value of 0 , so the vegetation distribution figure is extracted, then overlay analysis is carried out for NDVI figure, Tb distribution figure and the processed vegetation distribution figure. When profile data are extracted, the points whose value are 0 in vegetation distribution figure are knocked out, thus NDVI in vegetation coverage land surface and corresponding $\mathrm{Tb}$ value are acquired. Construction land is treated in a similar way. Fig 3 shows the feature profiles on vegetation, Fig 4 shows the feature profiles on construction.

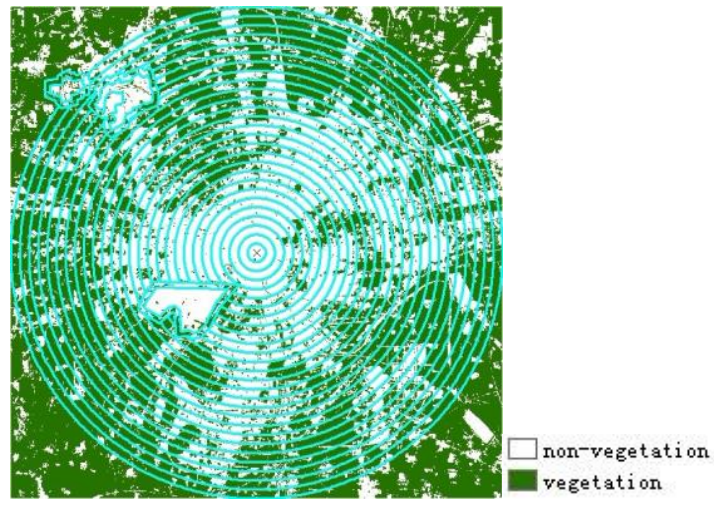

Fig 3 Feature profiles on vegetation

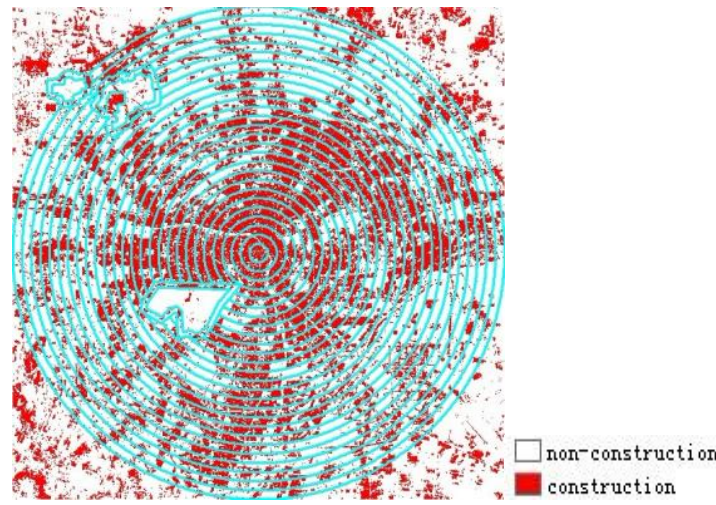

Fig 4 Feature profiles on construction

\section{CONSEQUENCE AND ANALYSIS}

\section{A. Space Distribution Character of Land Surface Brightness Temperature in Study Area}

Seen from Land Surface Brightness Temperature distribution diagram for study region (Diagram 2), red area (high temperature area) mainly distribute in the center part of city, because this area is prosperous commercial area or industrial area, the population density is relatively large, human activities are frequent and more heat is generated, what's more, the buildings are intensive in this region, and the heat is not easy to dissipate, so that the temperature in this area is higher than surrounding areas. The yellow area (middle temperature area) mainly distribute in the surrounding of the red area, this area is mainly villages and small residential areas. The light blue area (secondly low temperature) mainly distribute in suburb, agriculture use land and urban-rural-integration area, and the blue area (low temperature area) mainly distribute in mountainous areas and water bodies which are better in vegetation coverage. It is found that for the average brightness temperature of different land use types in study region, the highest one is $303.655 \mathrm{~K}$ of building use land, the secondly highest one is $299.053 \mathrm{~K}$ of vegetation and the lowest one is $297.722 \mathrm{~K}$ of water body through the overlay analysis of land use type diagram and $\mathrm{Tb}$ distribution diagram. 


\section{B. Analysis on the Influence of Water Body on Land Surface Brightness Temperature}

In order to explore the influence of water body on $\mathrm{Tb}$ of its surrounding area, Yunlong Lake and the surrounding area is chosen as a research object, 13 profiles are made in the north bank of Yunlong Lake in a regular of 30m intervals. A scatter diagram (Fig 5) is made by calculating $\mathrm{Tb}$ average value in each profile and the distance from the north of Yunlong Lake.

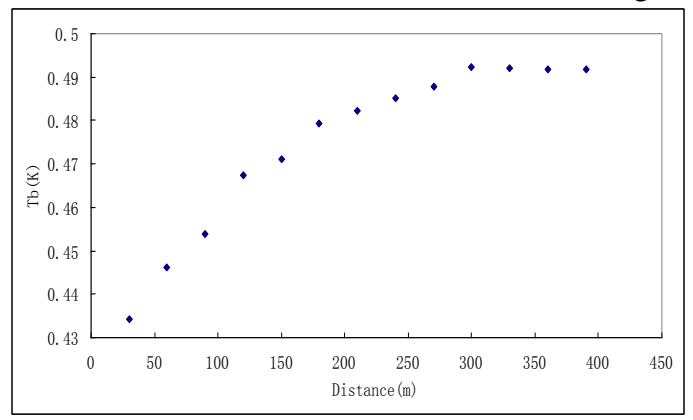

Fig 5 Changes of brightness temperature with distance

Table 1, while NDBI in Table 2, The results show that the Pearson coefficient between Tb and NDVI in all profiles are all negative number, while that between Tb and NDBI are all
When the distance increases to $300 \mathrm{~m}$, the brightness temperature does not increase following the increase of the distance; it can be considered that the influence radius of Yunlong Lake on the surrounding area is $300 \mathrm{~m}$. Therefore, in the following researches, water body influences can be knocked out based on the above conclusion.

\section{Relationship between Land Surface Characteristic Parameters and Corresponding $\mathrm{Tb}$}

\section{1) The Relationship of NDVI, NDBI and Tb}

As vegetation in first seven characteristic profiles are rare (as Fig 3), NDVI of vegetation land and the corresponding Tb value are extracted from the eighth profile whose radius is $4.0 \mathrm{~km}$; due to the wide distribution of building use land, NDBI of building land and the corresponding $\mathrm{Tb}$ value are extracted from the first profile whose radius is $0.5 \mathrm{~km}$, and the regression analysis is carried out on the extracted NDVI and $\mathrm{Tb}, \mathrm{NDBI}$ and Tb separately. The result is seen as Table 1 and Table 2. Where Y represents the brightness temperature, $\mathrm{X}$ means NDVI in positive number, through these we can see that Tb and NDVI has a significant negative correlation, Tb and NDVI has a significant positive correlation.

Table 1 Regressive relationship between brightness temperature and NDVI

\begin{tabular}{cccccc}
\hline $\begin{array}{c}\text { Profile } \\
\text { radius }(\mathrm{km})\end{array}$ & $\begin{array}{c}\text { Pearson } \\
\text { coefficient }\end{array}$ & Regression equation & $\begin{array}{c}\text { Profile } \\
\text { radius }(\mathrm{km})\end{array}$ & $\begin{array}{c}\text { Pearson } \\
\text { coefficient }\end{array}$ & Regression equation \\
\hline 4.0 & $-0.383^{* *}$ & $Y=-5.657 X+300.609$ & 9.0 & $-0.551^{* *}$ & $Y=-5.774 X+301.238$ \\
4.5 & $-0.268^{* *}$ & $Y=-4.288 X+300.586$ & 9.5 & $-0.577^{* *}$ & $Y=-6.528 X+301.529$ \\
5.0 & $-0.398^{* *}$ & $Y=-6.026 X+301.114$ & 10.0 & $-0.545^{* *}$ & $Y=-6.759 X+301.186$ \\
5.5 & $-0.358^{* *}$ & $Y=-4.332 X+300.649$ & 10.5 & $-0.584^{* *}$ & $Y=-7.341 X+301.443$ \\
6.0 & $-0.471^{* *}$ & $Y=-4.505 X+300.929$ & 11.0 & $-0.636^{* *}$ & $Y=-7.570 X+301.503$ \\
6.5 & $-0.463^{* *}$ & $Y=-6.570 X+301.346$ & 11.5 & $-0.525^{* *}$ & $Y=-6.178 X+301.060$ \\
7.0 & $-0.485^{* *}$ & $Y=-7.073 X+301.550$ & 12.0 & $-0.589^{* *}$ & $Y=-7.824 X+301.581$ \\
7.5 & $-0.48^{* *}$ & $Y=-7.147 X+301.503$ & 12.5 & $-0.652^{* *}$ & $Y=-6.981 X+301.645$ \\
8.0 & $-0.476^{* *}$ & $Y=-5.767 X+300.948$ & 13.0 & $-0.524^{* *}$ & $Y=-6.093 X+300.986$ \\
8.5 & $-0.571^{* *}$ & $Y=-6.882 X+301.746$ & 13.5 & $-0.572^{* *}$ & $Y=-6.667 X+301.239$ \\
\hline
\end{tabular}

Table 2 Regressive relationship between brightness temperature and NDBI

\begin{tabular}{cccccc}
\hline $\begin{array}{c}\text { Profile } \\
\text { radius }(\mathrm{km})\end{array}$ & $\begin{array}{c}\text { Pearson } \\
\text { coefficient }\end{array}$ & Regression equation & $\begin{array}{c}\text { Profile } \\
\text { Radius }(\mathrm{km})\end{array}$ & $\begin{array}{c}\text { Pearson } \\
\text { coefficient }\end{array}$ & Regression equation \\
\hline 0.5 & $0.141^{* *}$ & $Y=7.130 X+300.587$ & 7.5 & $0.347^{* * *}$ & $Y=7.378 X+299.888$ \\
1.0 & $0.141^{* *}$ & $Y=6.316 X+300.588$ & 8.0 & $0.471^{* *}$ & $Y=7.175 X+299.467$ \\
1.5 & $0.220^{* *}$ & $Y=5.599 X+300.118$ & 8.5 & $0.368^{* *}$ & $Y=7.224 X+299.658$ \\
2.0 & $0.214^{* *}$ & $Y=6.045 X+300.254$ & 9.0 & $0.330^{* *}$ & $Y=6.622 X+299.962$ \\
2.5 & $0.309^{* *}$ & $Y=5.970 X+299.935$ & 9.5 & $0.364^{* *}$ & $Y=7.179 X+299.563$ \\
3.0 & $0.309^{* *}$ & $Y=5.970 X+299.935$ & 10.0 & $0.396^{* *}$ & $Y=7.460 X+299.320$ \\
3.5 & $0.163^{* *}$ & $Y=7.111 X+300.559$ & 10.5 & $0.516^{* *}$ & $Y=8.078 X+299.218$ \\
4.0 & $0.371^{* *}$ & $Y=7.242 X+299.747$ & 11.0 & $0.437^{* *}$ & $Y=8.086 X+299.074$ \\
4.5 & $0.250^{* *}$ & $Y=6.173 X+300.182$ & 11.5 & $0.504^{* *}$ & $Y=8.659 X+299.194$ \\
5.0 & $0.333^{* *}$ & $Y=6.477 X+300.176$ & 12.0 & $0.353^{* *}$ & $Y=7.257 X+299.454$
\end{tabular}




\begin{tabular}{|c|c|c|c|c|c|}
\hline $\begin{array}{c}\text { Profile } \\
\text { radius }(\mathrm{km})\end{array}$ & $\begin{array}{c}\text { Pearson } \\
\text { coefficient }\end{array}$ & Regression equation & $\begin{array}{c}\text { Profile } \\
\text { Radius }(\mathrm{km})\end{array}$ & $\begin{array}{c}\text { Pearson } \\
\text { coefficient }\end{array}$ & Regression equation \\
\hline 5.5 & $0.255^{* *}$ & $Y=5.900 X+300.563$ & 12.5 & $0.348^{* * *}$ & $Y=7.574 X+299.379$ \\
\hline 6.0 & $0.449^{* *}$ & $Y=7.604 X+299.399$ & 13.0 & $0.289^{* *}$ & $Y=7.713 X+299.061$ \\
\hline 6.5 & $0.341^{* *}$ & $Y=7.574 X+299.742$ & 13.5 & $0.272^{* *}$ & $Y=7.567 X+299.411$ \\
\hline 7.0 & $0.481^{* *}$ & $Y=7.857 X+299.705$ & & & \\
\hline
\end{tabular}

\section{2) Analysis on the Change of Pearson Coefficient}

It is known from Table 1 and Table 2 that $\mathrm{Tb}$ and NDVI, $\mathrm{Tb}$ and NDBI have significant correlation but the correlation coefficient in each profile is different, which verifies that the correlation of $\mathrm{Tb}$ and NDVI and the correlation of $\mathrm{Tb}$ and NDBI have differences in space. In order to find out the space difference of correlation, the analysis on the absolute value of Pearson coefficient of each equation in Table 1, Pearson coefficient of each equation in Table 2 and the radius of corresponding profiles are carried out and a scatter diagram is made (Fig 6).

It is seen that Pearson coefficient increases with the increase of the profile radius; the correlation of $\mathrm{Tb}$ and NDVI and the correlation of $\mathrm{Tb}$ and NDBI represent the gradual

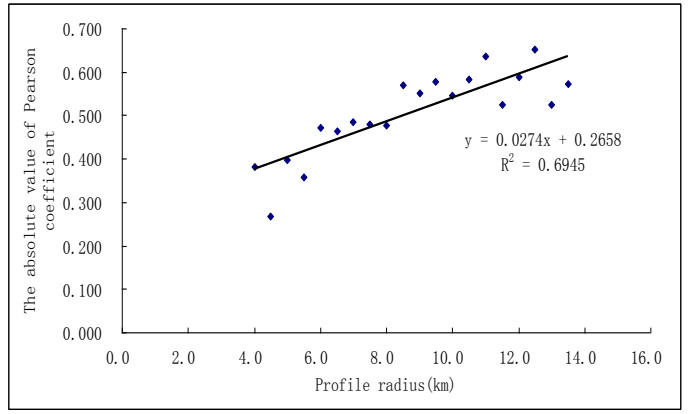

increasing trend from center profile to edge profile; for NDBI, the reason is possibly that the change range of NDBI increases with the increase of the profile radius; as buildings are intensive in center profile, NDBI is high there, so no matter how Tb changes NDBI is fluctuated in a definite value; while the edge profile is influenced by bare land, fluctuation range of NDBI value is large, so that Pearson is higher than the center profile; besides, as the pixel number in center profile is possibly less than that in edge profile, exceptional value influences regression relation largely, so that the Pearson coefficient is small. For NDVI, the influence of exceptional value takes the main part.

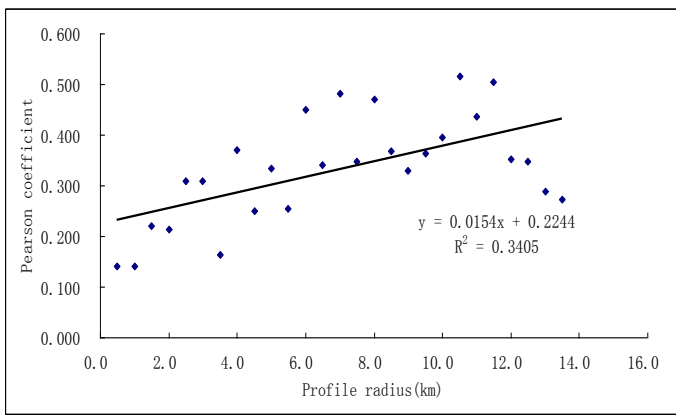

Fig 6 Changes Pearson coefficient with profiles radius

\section{3) Horizontal Comparison of the Correlation Between} $N D V I, N D B I$ and $T b$

In order to analyze the correlation degree of NDVI and $\mathrm{Tb} 、 \mathrm{NDBI}$ and $\mathrm{Tb}$ and the contribution ability of these two land surface character parameters on brightness temperature, Compare Table 1 with Table 2 in Pearson coefficient and slope rate of each regression equation, the results are shown in Fig 7 and Fig 8 .

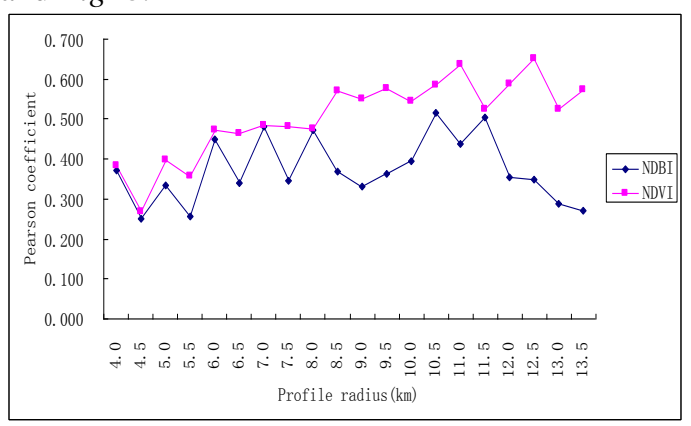

Fig 7 Comparison of Pearson coefficient Figure

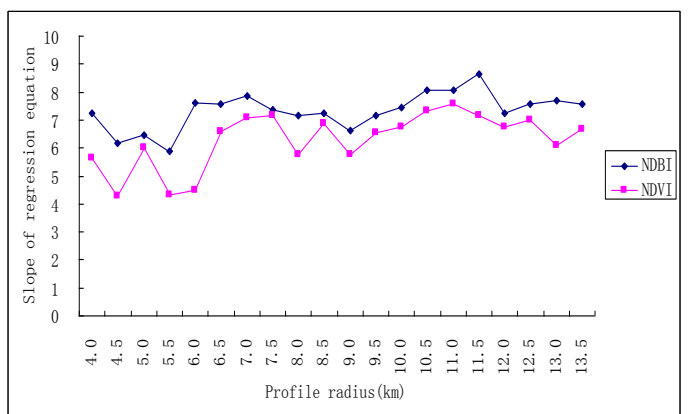

Fig 8 Comparison of slope of regression equation

It is seen from Fig 7 that Pearson coefficient of NDVI and $\mathrm{Tb}$ is larger than that of NDBI and $\mathrm{Tb}$ in each profile, which explains that NDVI and $\mathrm{Tb}$ has stronger correlation; it is known from Fig 8that the slope rate of regression equation of $\mathrm{NDBI}$ and $\mathrm{Tb}$ is larger than that of NDVI and $\mathrm{Tb}$ in each profile, which explains that the contribution rate of NDBI to brightness temperature is larger than NDVI; that is to say, the reduced $\mathrm{Tb}$ value by the increase of 1 unit of NDVI is not larger than the reduced $\mathrm{Tb}$ value by the decrease of 1 unit of NDBI, which can provide 
some references for future city planning and green land planning of Xuzhou city.

\section{CONCLUSION}

In the study area, the brightness temperature of city is obviously higher than that of suburb; and the sequence of the average brightness temperature from high to low is building land, vegetation and water body.

Water body has cooling effect on its surrounding environment, and the effect is relative to distance. It is found that the influence radius of Yunlong Lake on brightness temperature is around $300 \mathrm{~m}$.

NDVI and Tb represent negative correlation, while NDBI and $\mathrm{Tb}$ represent positive correlation, and the correlation coefficient increases with the increase of profile radius by studying the relation of NDVI and $\mathrm{Tb}$ and the relation of NDBI and Tb.

Horizontal comparison of NDVI and NDBI is carried out, and it is found that the former is higher than that the latter in the correlation with $\mathrm{Tb}$. But for the contribution ability to $\mathrm{Tb}$, the former is weaker than the latter.

\section{COPYRIGHT FORMS}

Chen Fu(1974-), Male, PhD, Professor.

Research Area: Ecological Restoration and Sustainable Management of Land Use.

Adress: Low Carbon Engineering Institute, China University of Mining and Technology 4th Floor, Hi-tech Center Building of the University Science \& Technology Park of CUMT Xuzhou, Jiangsu, China.

postcode: 221008

Phone: 13951946510
Email: chenfu@cumt.edu.cn

Fax: 0516-83883501

\section{REFERENCES}

[1] PAN Jing-hu, HAN Wen-chao. Urban expansion and its heat island response in Lanzhou City based on remote sensing analysis[J], Chinese Journal of Ecology, 2011,30(11):2597-2603.

[2] MORRIS C J G, SIMMONDS I, PLUMMER N. Quantification of the influences of wind and cloud on the nocturnal urban heat island of a large city[J]. Journal of Applied Meteorology articles, 2001, 40(2):169-182.

[3] RAJAGOPALAN P, WONG $\mathrm{N} H$, CHEONG $\mathrm{K}$ W $\mathrm{D}$. Microclimatic modeling of the urban thermal environment of Singapore to mitigate urban heat island[J]. Solar Energy, 2008,82(8):727-745.

[4] WENG Qi hao. Fractal analysis of satellite-detected urban heat island effect[J]. Photogram Metric Engineering \& Remote Sensing, 2003, 69(5):555-566.

[5] Lo C P, Quattrochi D A, Luvall J C. Application of highresolution thermal infrared remote sensing and GIS to assess the urban heat island effect[J]. International Journal of Remote Sensing, 1997,18(2):287-303.

[6] ZHA Yong, NI Shao-xiang, YANG Shan . An Effective Approach to Automatically Extract Urban Land-use from TM lmagery[J]. Journal of Remote Sensing, 2003,7(1):37-40.

[7] WU Peng-fei1, WANG Mao-jun, ZHANG Xue-xia. Distribution of urban heat island effects based on normalized difference built-up index in Beijing city[J]. Ecology and Environmental Sciences, 2009, 18(4):1325-1331.

[8] Qin Zhi-hao, Zhang Ming-hua, Arnon Karnieli,Pedro Berliner. Mono-window Algorithm for Retrieving Land Surface Temperature from Landsat TM6 data[J]. Acta Geographica Sinica, 2001, 56(4):456-466. 